\title{
Artificial cervical disc replacement - An update
}

\author{
C. Mehren, H. M. Mayer \\ Spine Centre Munich, Orthozentrum München, Germany
}

\section{Rationals for total disc replacement}

Dynamic reconstruction of a degenerative "functional spinal unit" (FSU) is a rapidly growing field in spinal surgery.

So far anterior cervical discectomy and fusion (ACDF), first described by Smith and Robinson ${ }^{[1]}$ and by Cloward ${ }^{[2]}$ in the $1950 \mathrm{~s}$, is the most common surgical procedure proven successful in the treatment of symptoms caused by cervical degenerative disc disease (DDD) including disc herniations and other compressive pathologies.

The main goal of these techniques is the decompression of neural structures and to re-establish segmental stability with restoration of the physiologic curvature of the treated segment(s). Restoration of stability and sagittal rebalancing can only be achieved with the fusion of one or more cervical segments. In the cervical as well as in the lumbar spine there has been increasing concern about acceleration of adjacent segment degeneration which might result in further surgical procedures.

In the late $1980 \mathrm{~s}$ Cummins ${ }^{[3]}$ tried to address the problem of maintaining motion in the cervical spine after surgery by introducing a simple ball and a socket type of cervical joint with entirely congruent surfaces. This technique preserved in most cases a limited segmental motion and it was concluded that further investigations were warranted to prove the efficacy of this procedure. The promising early results seen in prospective randomised studies of total disc replacement in the lumbar spine have encouraged the development of similar solutions for the cervical spine in order to create an alternative to fusion procedures. $^{[4,5,6]}$

\section{Indications and presumed goals of total cervical disc replacement}

The indications for cervical total disc replacement are basically the same as for a ACDF with a few exceptions. The patient should have a symptomatic disc, which lead to arm and/or neck pain and/or radiculopathy with sensomotoric deficits. These symptoms can be caused by a herniated disc and/or osteophytes compressing adjacent nerves or the spinal cord. ${ }^{[7,8]}$
The basic principle of cervical spine surgery continues to include adequate decompression of the neural structures for the ACDF as well as for disc replacement. At this time only single level cervical disease is being included to the U.S. clinical trial in opposite to the European trials.

There is general consensus, that the ability of an artificial disc to correct deformities and to restore physiological lordosis is limited due to the non- / semi-conta 'strained designs (see below). It is also clear, that a total disc implant is not able to resist translational instabilities, so it is contraindicated in all types of anterolisthesis as well as in patients who have had a laminectomy. The currently accepted inclusion- and exclusion criteria are listed in (Table 1).

In comparison to a fusion a total cervical disc replacement maintains segmental mobility and thus might decrease the incidence of symptomatic adjacent level degeneration. This however is still a working hypothesis and not supported by any of the studies published hitherto.

Other advantages of the artificial cervical disc over a fusion are the eliminated need for a bone graft with all its side effects and the possibility of an earlier postoperative neck motion with a potentially faster return to normal activities.

\section{Preop workup}

There is a general consensus that plain x-rays including flexion/ extension views are necessary as well as MRI to prove the discogenic patho-morphology.

The role of semi-invasive diagnostic measures such as diagnostic injections and / or discography is not clear.

\section{The players}

There are currently 5 types of total disc implants for the cervical spine available worldwide. Three are in IDE studies in the U.S. and are waiting for approval by the Food and Drug Administration (FDA) at the moment..$^{[9,10,11]}$

Prestige (Medtronic Sofamor Danek, Memphis, USA) (Figure 1)

The Prestige I cervical prosthesis (also named Frenchay artificial joint), which is a modified version of the original Cummins 
Table 1: Inclusion/exclusion criteria currently 2005 accepted for total disc replacement

\section{Inclusion criteria}

- DDD requiring surgical treatment at one level (in the FDA trails) to three levels from C3-Th1 for symptoms or signs of cervical radiculopathy and/or myelopathy, with or without axial neck pain

- Failed conservative treatment lasting at least 6 weeks for any one or more of: - disc herniation with radiculopathy

- spondylotic radiculopathy

- disc herniation with myelopathy

- sponylotic myelopathy

- Compressive lesion must be proven by MRI/CT or myelography

- 18 to 65 years of age

- non-discogenic pain sources shpuld be excluded

\section{Exclusion criteria}

- Post-laminectomy with kyphotic deformity

- Translational instability

- Ankylosing spondylitis, rheumatoid arthritis

- Ossification of the posterior longitudinal ligament or diffuse hyperostosis

- Insulin-requiring diabetes mellitus

- Infection

- Pregnancy

Metabolic bone diseases

prosthesis (1991-1996), was developed 1998 and is a two-piece prosthesis constructed of stainless steel and employs a ball-ingroove articulation. The lower component is a shallow ellipsoid saucer to permit translation within three degrees of freedom for translation and rotation. Rotation of the upper component is achieved by allowing the hemisphere of the joint to glide in the saucer with metal-on-metal articulating surfaces and variable point loading. Because of the incongruent interface the upper vertebral component is permitted passively to find its own axis of rotation as determined by the facet joints and coupled motion of adjacent vertebrae. The two articulating components of the joints are fixed into the vertebral bodies with a locking screw. ${ }^{[12,13]}$

Throughout further studies the Prestige I effectively maintained motion and assessment 4 years after surgery demonstrated a positive result in the Neck Disability Index (NDI), visual analog scales (VAS) for neck and arm pain and the Short Form (SF) 36 mental and physical component scores. ${ }^{[14]}$

The Prestige II was designed in 1999. The characteristics and

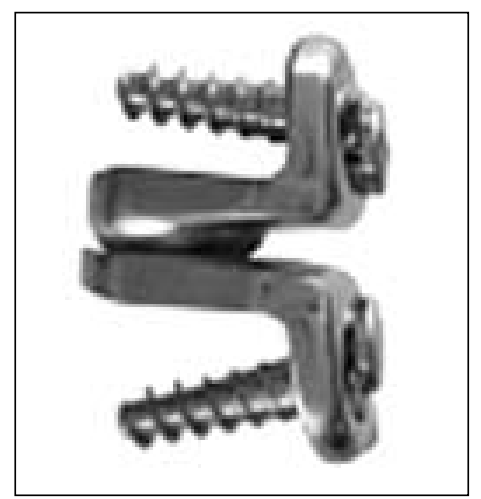

Figure 1: Prestige $\mathrm{I}^{\mathrm{TM}}$ (Medtronic Sofamor Danek, Memphis, USA) two-piece prosthesis with metal-on-metal articulating surfaces main difference to its predecessor is a more anatomic end-plate design, which was roughened to improve bony ingrowth. ${ }^{[12]}$ Porchet et $\mathrm{a}^{[15]}$ compared in a prospective, randomized clinical trial the Prestige II Cervical Disc with ACDF for the treatment of singlelevel disease. Radiographic results show that the Prestige II disc maintains motion at the treated level without adjacent-segment compromise.

The Prestige ST (Figure 2) became available in 2002. The major design change was a reduction in the height of each anterior flange of $2 \mathrm{~mm}$. This device is currently in U.S. clinical trials by the FDA. It is available in four different heights $(6$ to $9 \mathrm{~mm})$ and two choices of depth (12 and $14 \mathrm{~mm}$ ). The width is consistent with $17.8 \mathrm{~mm}$. $^{[10,12]}$

The most recent development is the Prestige STLP (Figure 3). This version differs from its predecessors above all because of the possibility of multilevel implantation. The fixation is now achieved by a set of rails that are placed on the prosthesis - bone contact surface, what eliminates the anterior profile of the device. ${ }^{[12]}$

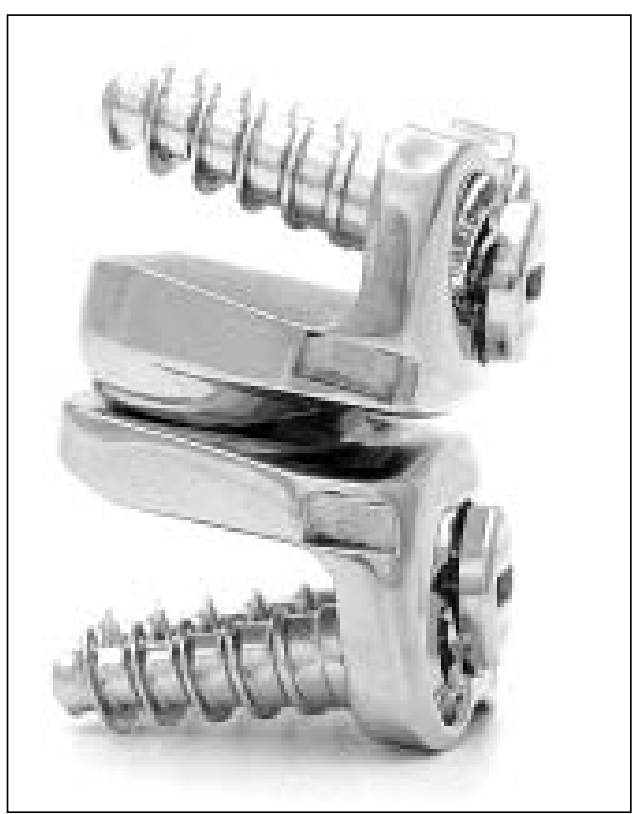

Figure 2: Prestige $\mathrm{ST}^{\mathrm{TM}}$ (Medtronic Sofamor Danek, Memphis, USA) anatomic end-plate design with reduced endplate thickness

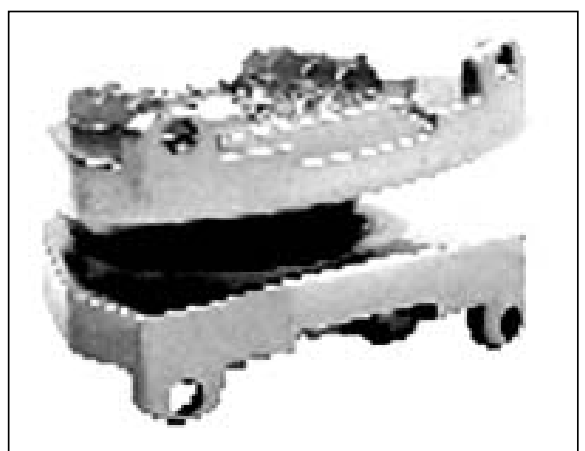

Figure 3: Prestige STLP ${ }^{\text {TM }}$ (Medtronic Sofamor Danek, Memphis, USA) possibility of multilevel implantation 


\section{Cervicore (SpineCore, Summit, USA) (Figure 4)}

Another disc replacement design using a metal-on-metal joint to imitate normal motion at the cervical disc space is the Cervicore prosthesis. The Cervicore is a metal-on-metal design having a saddle-shaped bearing surface. This surface permits the device to maintain a centre of rotation for flexion/extension in the vertebral body below and simultaneously maintaining a centre of rotation in the bone above for lateral bending. ${ }^{[10]}$

Till now there are no clinical data available at the time this review is written. So far this device is not yet in U.S. clinical trails.

\section{ProDisc-C (Spine Solution, Paoli, USA) (Figure 5)}

The ProDisc-C is constructed of two cobalt-chrome metal end plates and a fixed polyethylene core that provides coupled motion without independent translation when the device is implanted.

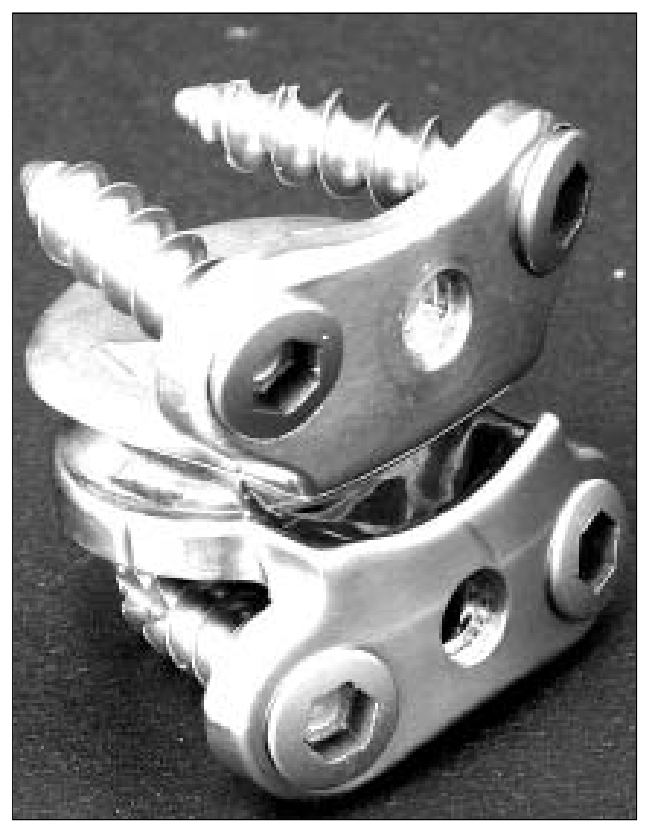

Figure 4: Cervicore ${ }^{\mathrm{TM}}$ (SpineCore, Summit, USA) metal-on-metal design having a saddle-shaped bearing surface

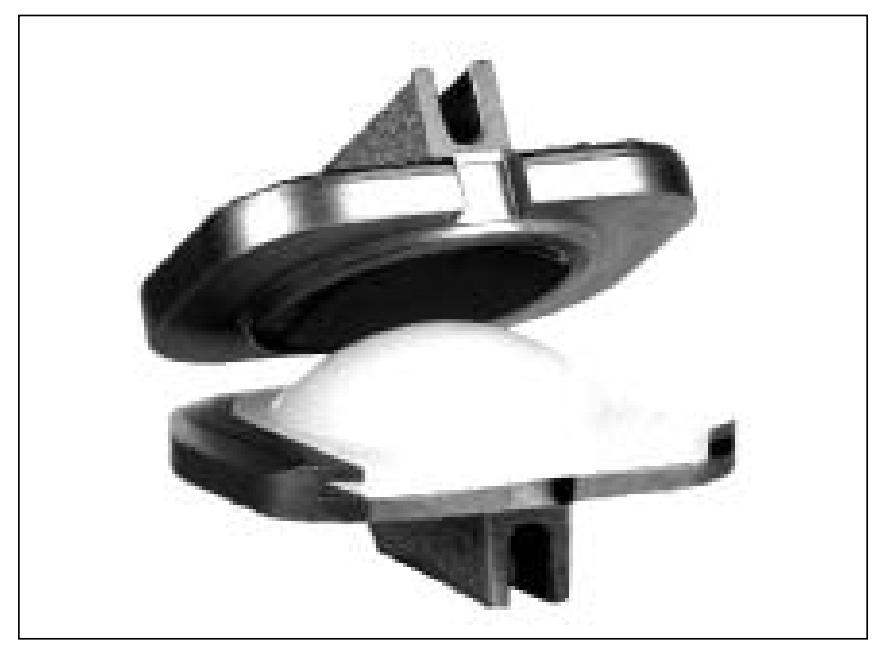

Figure 5: ProDisc $\mathrm{C}^{\mathrm{TM}}$ (Spine Solution, Paoli, USA) metal-onpolyethylene semiconstrained design
The ProDisc-C maintains a single centre of rotation in the vertebral bone below the intervertebral space. It comes in six sizes of footprints. Implantation takes place by inserting a keel in a slot of the cranial and caudal vertebral body. The surfaces of the prosthesis towards the bones bear a plasma-spray titanium layer for secondary fixation. ${ }^{[16,17,10]}$

\section{Bryan Disc (Medtronic Sofamor Danek, Memphis, USA) (Figure 6)}

The Bryan cervical disc is comprised of a polycarbonate, polyurethane core situated between two convex porous coated titanium shells, encapsulated around the periphery by a polymer sheath. The design of this single-piece prosthesis allows a normal range of motion in flexion/extension, lateral bending, rotation and translation as well as coupled motions. Initial stability is achieved by precision milling of the vertebral end plates and long term stability by bone growth into the porous coated surfaces. ${ }^{[18,10]}$

Over 5000 Bryan discs have been implanted worldwide so far. ${ }^{[10]}$ At the 24- month evaluation of 97 patients with single level disc replacement $70 \%$ had excellent results based on Odom's criteria. ${ }^{[19,20]}$ Johnson et al ${ }^{[21]}$ showed that patients who underwent arthroplasty with this artificial disc had a focal loss of lordosis at the treated level. But there was no significant change in the overall sagittal curvature of the cervical spine.

The Bryan Disc is currently in U.S. clinical trails.

\section{PCM (Cervitech, Roundhill, USA) (Figure 7)}

The Porous Coated Motion (PCM) is a polyethylene-on-metal design which includes a uniarticular design with one center of rotation maintained below the intervertebral space. The end plates are manufactured from cobalt-chrome alloy, the outside of the components feature a TiCaP coating. Primary stability is assured by a press-fit implantation. ${ }^{[17,11]} \mathrm{McAfee}{ }^{[8]}$ published a clinical study of 23 patients, who underwent a total of 32 PCM cervical arthroplasties. At 9 month follow up over $70 \%$ had 15 points or more improvement as compared to the preoperative Ostwestry

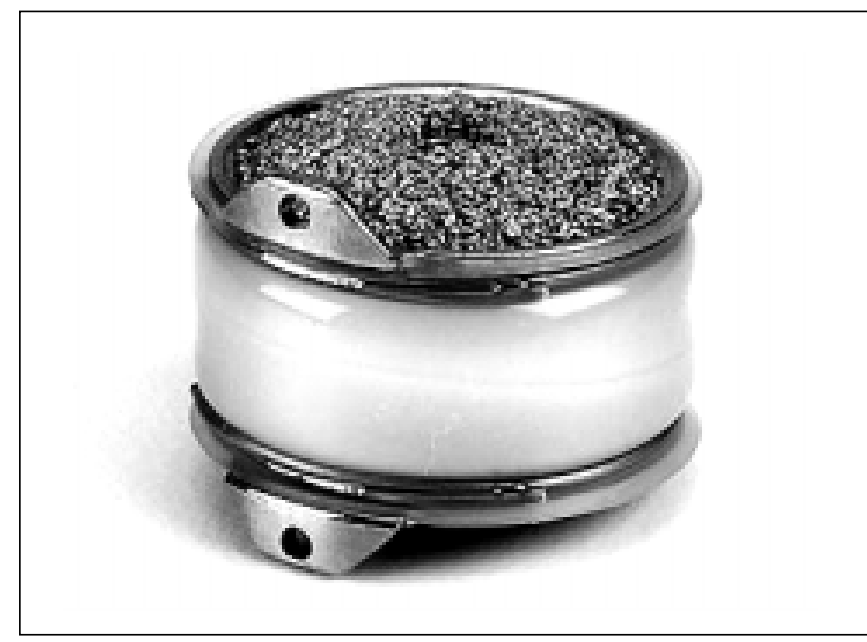

Figure 6: Bryan ${ }^{\mathrm{TM}}$ Disc (Medtronic Sofamor Danek, Memphis, USA) single-piece prosthesis: metal and polyurethane device 


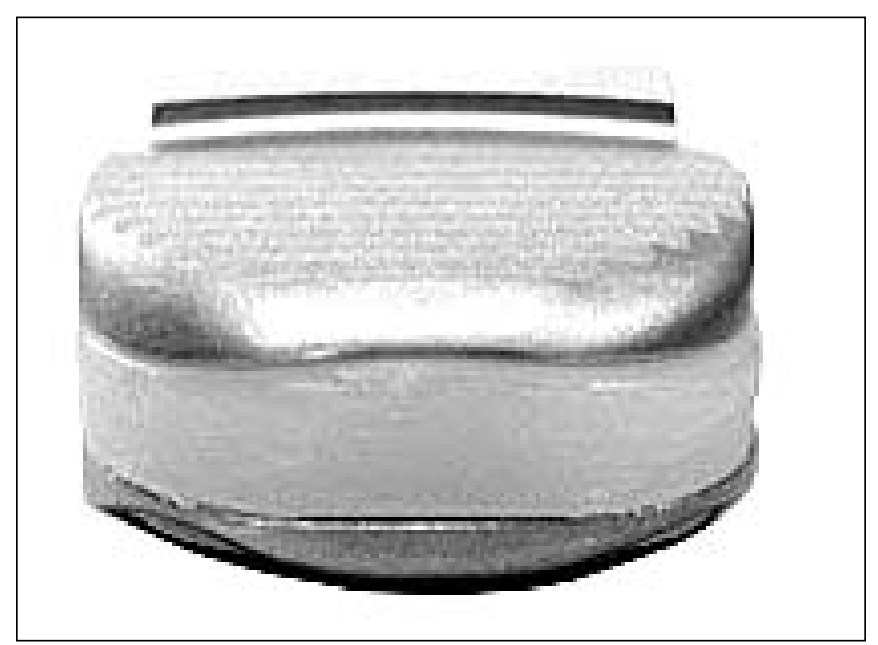

Figure 7: $\mathrm{PCM}^{\mathrm{TM}}$ (Porous coated motion) (Cervitech, Roundhill, USA) polyethylene-on-metal mono-articular design

Neck Disability Index. Over $80 \%$ had greater then $20 \%$ improvement on VAS. All 32 prosthesis demonstrated successful ingrowth with no evidence of loosening.

The PCM is not yet in an FDA-controlled study.

\section{Facts and open questions \\ Adjacent-level degeneration}

Long-term data (up to 10 years) suggests that there are significant radiographic and clinical consequences associated with fusion. Hilibrand et al ${ }^{[22]}$ provide perhaps the greatest insight to this problem. These investigators identified symptomatic adjacentlevel disease occurring at an average rate of $2.9 \%$ per year during the first 10 post-fusion years for 374 patients in their study group. Two-third of this patients requiring reoperation. The most likely levels to develop adjacent segment disease were $\mathrm{C} 5 / 6$ and $\mathrm{C6} / 7$. Goffin et al ${ }^{[23]}$ identified $92 \%$ rate of adjacent-level radiological degeneration after fusion over a mean of 8.6 years.

Biomechanical investigations support the clinical observations that fusions are associated with adjacent-level degeneration. ${ }^{[24,25]}$ The disc pressures at the adjacent segments before and after fusion at $\mathrm{C} 5 / 6$ were measured by Eck et al. ${ }^{[26]}$ They found a $73 \%$ increase in cranial and $45 \%$ in caudal disc pressures during flexion and an increased intervertebral motion especially rostrally. Another investigation done by Fuller et $\mathrm{al}^{[27]}$ found an increase up to $40 \%$ in the adjacent levels.

Although only a small group of patients require surgery for adjacent level decompensation, it seem worthwhile to prevent adjacent level disease as far as possible.

Cervical disc replacement has been shown to normalize adjacent level segment motion in biomechanical studies. Puttlitz et al ${ }^{[18]}$ demonstrated in cadaveric spines that a ball-and-socket design prosthesis can replicate physiologic motion at the affected and adjacent levels in flexion/extension and coupled motion. Nearly identical findings were reported by DiAngelo et al ${ }^{[28,29]}$ with Pro Disc C. These studies support the working hypothesis, that the preservation of motion in the diseased segment might preserve motion in the adjacent segment(s).

\section{Material consideration}

Much of the background for the development for these implants is drawn from the literature of other joint replacements that have been in evaluation and use for decades. At the moment there are two different disc designs available. One general artificial disc design comprises metal endplates with an intervening low friction polymer to allow motion between the polished metal surface and the polymer. The ProDisc C and the PCM device use Polyethylene (PE), which is well known from other types of arthroplasty such as in the hip or in the knee.

The Bryan Disc is a metal on Polyurethan device. This comprises application of a softer polymer intended to provide not only motion, but shock absorption as well.

The other disc implant types are metal-on-metal joints. The Prestige and the Cervicore are representatives for these kind of devices.

The problem of aseptic loosening of arthroplasties due to wear debris is well known in the literature. ${ }^{[30,31]}$ Clinical reports and further investigations have found such wear debris to be no significant problem in patients after total lumbar disc replacement. ${ }^{[32,33,34,17]}$ It must be considered however, that most of the studies are shorter than the expected standing times of total artificial lumbar discs. This probably will be verified in the cervical spine as well due to lower ranges of motion and loads as compared to total hip or knee arthroplasties. ${ }^{[30]}$

\section{Summary}

Anterior cervical discectomy and fusion is a reliable procedure with excellent clinical and radiological outcomes in $85-95 \%$ of the patients. ${ }^{[35,36]}$ It is a procedure with a low peri-and postoperative complication rate. ${ }^{[5,6,7]}$

Thus, these results will be hard to beat by any type of total disc replacement.

The crucial points which will probably decide the fate of total cervical disc replacement is the percentage of spontaneous fusion over time, the limitations in restoring disturbed curvatures, intraoperative technology and last not least the pricing of the implants.

So far, it seems to be promising technology in the cervical spine as in the lumbar spine which however has to stand the proof of time.

\section{References}

1. Smith GW, Robinson RA. The treatment of certain cervical-spine disorders by anterior removal of the intervertebral dise and interbody fusion. J Bone Joint Surg Am 1958;40:607-24.

2. Cloward RB. The anterior approach for removal of ruptured cervical disks. J Neurosurg 1958;15:602-17.

3. Cummins BH, Robertson JT, Gill SS. Surgical experience with an implanted artificial cervical joint. J Neurosurg 1998;88:943-8.

4. Delamarter RB, Fribourg DM, Kanim LE, Bae H. ProDise artificial total lumbar dise replacement: introduction and early clinical results from the United States clinical trial. Spine $2003 ; 28: 167-75$.

5. Mayer HM, Wiechert K, Korge A, Qose I. Minimally invasive total dise replacement: surgical technique and preliminary clinical results. Eur Spine J 2002;11:S12430 . 
6. Tropinano P, Huang RC, Girardi FP, Cammisa FP, Marnay T. Lumbar total dise replacement. Seven to eleven-year follow-up. J Bone Joint Surg Am $2005 ; 87$ A:490-6.

7. McAfee PC. The indications for lumbar and cervical dise replacement. Spine .J $2004 ; 4: 177 \mathrm{~S}-81 \mathrm{~S}$.

8. www.spine-health.com/research/artificialdise/artdiscs03.html

9. $\quad$ Anderson PA, Rouleau JP. Intervertebral disc arthroplasty. Spine 2004;29:2779_ 86.

10. Singh K, Vaccaro AR, Albert T.J. Assessing the potential impact of total disc arthroplasty on surgeon practice patterns in North America. Spine J 2004;4:195S$201 \mathrm{~s}$.

11. www.spine-health.com/research/artificialdisc/artdises02.html

12. Traynelis VC. The Prestige cervical disc replacement. Spine .J 2004;4:310S-4S

13. Wigfield CC, Gill SS, Nelson RJ, Metcalf NH, Robertson JT. The new Frenchay artificial cervical joint:results from a two-year pilot study. Spine 2002;27:2446-52.

14. Robertson JT, Metcalf NH. Long-term outcome after implantation of the Prestige I disc in an end-stage indication:4-year results from a pilot study. Neurosurg Focus 2004;17:E10

15. Porchet F, Metcalf NH. Clinical outcomes with the Prestige II cervical disc:preliminary results from a prospective randomized clinical trial. Neurosurg Focus (United States) 2004;17:6

16. Link HD, McAfee PC, Pimenta L. Choosing a cervical disc replacement. Spine J 2004;4:294S-302S

17. Puttlitz CM, Rousseau MA, Xu Z, Hu S, Tay BK, Lotz JC. Intervertebral dise replacement maintains cervical spine kineties. Spine 2004;29:2809-14.

18. Bryan VE .Jr. Cervical motion segment replacement. Eur Spine .J 2002;11:S92-7.

19. Guver RD, Ohnmeiss DD. Intervertebral disc prostheses. Spine 2003;28:S15-23.

20. Johnson JP, Lauryssen C, Cambron HO, Pashman R, Regan J.J, Anand N, et al. Sagittal alignment and the Bryan cervical artificial dise. Neurosurg Focus 2004; $17: \mathrm{E} 14$

21. Hilibrand AS, Carlson GD, Palumbo MA, Jones PK, Bohlman HH. Radiculopathy and myelopathy at segments adjacent to the site of a previous anterior cervical arthrodesis. J Bone Joint Surg Am (United States) 1999;81:519-28.

22. Goffin J, Casey A, Kehr P, Liebig K, Lind B, Logroscino C, et al. Preliminary clinical experience with the Bryan Cervical Disc Prosthesis. Neurosurgery (United States). 2002;51:840-5; discussion 845-7.

23. Ishihara H, Kanamori M, Kawaguchi Y, Nakamura H, Kimura T. Adjacent segment disease after anterior cervical interbody fusion. Spine .J (United States) $2004 ; 4: 624-8$.

24. Wigfield C, Gill S, Nelson R, Langdon I, Metcalf N, Robertson .J. Influence of an artificial cervical joint compared with fusion on adjacent-level motion in the treatment of degenerative cervical disc disease. J Neurosurg Spine 2002;96:17-21.

25. Eck JC, Humphrevs SC, Lim TH, Jeong ST, Kim JG, Hodges SD, et al. Biomechanica study on the effect of cervical spine fusion on adjacent-level intradiscal pressure and segmental motion. Spine (United States) 2002;27:2431-4.

26. Fuller DA, Kirkpatrick JS, Emery SE, Wilber RG, Davy DT. A kinematic study of the cervical spine before and after segmental arthrodesis. Spine 1998;23:164956.

27. Di Angelo DJ, Foley KT, Morrow BR, Schwab JS, Song J, German JW, et al. In vitro biomechanies of cervical dise arthroplasty with the ProDise-C total dise implant. Neurosurg Focus (United States) 2004;17:7.

28. Di Angelo DJ, Roberston JT, Metcalf NH, McVay B.J, Davis RC. Biomechanical testing of an artificial cervical joint and an anterior cervical plate. J Spinal Disord Tech (United States) 2003;16:314-23.

29. Taksali S, Grauer JN, Vaccaro AR. Material considerations for intervertebral disc replacement implants. Spine J (United States) 2004:4:231S-8S.

30. Willert HG, Buchhorn GH, Hess T. The significance of wear and material fatique in loosening of hip prosthesis. Orthopade 1989;18:S350-69.

31. Anderson PA, Rouleau JP, Bryan VE. Wear analysis of the Bryan Cervical Disc prosthesis. Spine 2003;28:S186-94.

32. Anderson PA, Sasso RC, Rouleau JP, Carlson CS, Goffin J. The Bryan Cervical Disc:wear properties and early clinical results. Spine .J 2004;4:303S-9S.

33. Anderson PA, Rouleau JP, Toth JM, Riew KD. A comparison of simulator-tested and -retrieved cervical disc prostheses. Invited submission from the Joint Section Meeting on Disorders of the Spine and Peripheral Nerves, March 2004. J Neurosurg Spine (United States) 2004;1:202-10.

34. Mayer HM. Cervical Disk Replacement SpineArt - A Spine Arthroplasty Magazine No 1/2004 Springer-Verlag Berlin: Heidelberg; 2004

35. Moreland DB, Asch HL, Clabeaux DE, Castiglia G.J, Czajka GA, Lewis P., et al Anterior cervical discectomy and fusion with implantable titanium cage: initial impressions, patient outcomes and comparison to fusion with allograft. Spine .J 2004;4:184-91

36. Albert T.J, Eichenbaum MD. Goals of cervical disc replacement. Spine J 2004:4:292S-3S

37. Duggal N, Pickett GE, Mitsis DK, Keller JL. Early clinical and biomechanical results following cervical arthroplasty. Neurosurg Focus (United States) 2004;17:9.

38. Goffin J, Geusens E, Vantomme N, Quintens E, Waerzeggers Y, Depreitere B, et al. Long-term follow-up after interbody fusion of the cervical spine. J Spinal Disord Tech (United States) 2004;17:79-85.

39. Goffin J, van Calenbergh F, van Loon J, Casey A, Kehr P, Liebig K, et al. Intermediate follow-up after treatment of degenerative disc disease with the Bryan Cervical Disc Prosthesis:single-level and bi-level. Spine (United States) 2003:28:2673-8.

40. Hilibrand AS, Robbins M. Adjacent segment degeneration and adjacent segment disease: the consequences of spinal fusion? Spine J (United States) 2004;4:190S$4 \mathrm{~S}$.

41. Pickett GE, Mitsis DK, Sekhon LH, Sears WR, Duggal N. Effects of a cervical disc prosthesis on segmental and cervical spine alignment. Neurosurg Focus (United States) $2004 ; 17: 5$. 